\title{
Evolution Characteristics of Urban Functional Land and Its Development Strategy in Oasis City: A Case of Zhangye City, the Hexi Corridors, China
}

\author{
Liang Feng ${ }^{1}$, Li Qianguo ${ }^{2}$, Shi Peiji ${ }^{1, *}$ \\ ${ }^{1}$ College of Geography and Environment Science, Northwest Normal University, Lanzhou, China \\ ${ }^{2}$ Gansu Institute of Land and Resources Planning, Lanzhou, China
}

Email address:

liangfeng_nwnu@126.com (Liang Feng), lqgxsd@126.com (Li Qianguo),xbsdspj@163.com (Shi Peiji)

*Corresponding author

\section{To cite this article:}

Liang Feng, Li Qianguo, Shi Peiji. Evolution Characteristics of Urban Functional Land and Its Development Strategy in Oasis City: A Case of Zhangye City, the Hexi Corridors, China. Earth Sciences. Vol. 6, No. 5, 2017, pp. 69-74. doi: 10.11648/j.earth.20170605.12

Received: July 18, 2017; Accepted: August 23, 2017; Published: September 4, 2017

\begin{abstract}
The evolution of urban functional land is the spatial reflection of urban functional agglomeration and diffusion, it can profoundly reveal the internal characteristics of urban expansion. This paper applies spatial analysis tools of GIS to explore the spatial-temporal evolution characteristics of residential land, industrial land and public service land in Zhangye City since 1981 so as to provide effective development strategies for the sustainable development of oasis city. The results show that: 1) The urban residential land and public service facilities land have been gradually increasing, and there is a trend of spatial evolution that is spreading from the centre to periphery. However, industry and storage land increased first and decreased after, and it is from dispersing to agglomeration in spatial. The industry and storage land gathers in the industrial park. 2) Zhangye city should break through the development model of a single core and promote the compact development of urban space to form the full-featured urban spatial structure in the future.
\end{abstract}

Keywords: Urban Functional Land, Urban Spatial Structure, Evolution; Regulation Strategy, Downtown of Zhangye City

\section{Introduction}

The urbanization of China is in the stage of rapid development. The urban space structure is facing a critical time of transformation, and relevant research has attracted increasingly attention from all circles [1]. However, urban function land is the essential factor of the urban material space and the space carrier of the urban function area [2]. Studying the evolution of the urban functional land can not only clarify the spatial response of the urban spatial expansion and urban functional land's agglomeration and diffusion, but can reveal the inherent characteristics and deeply rules of urban spatial expansion [3]. The transformation and evolution and of a kind of urban functional land reflects its corresponding urban function, and the evolution and mutual transformation of all kind of urban functional land reflect the temporal and spatial evolution and expansion of urban various function [2]. Throughout the domestic and foreign research for urban functional land, it can be found that they are mostly concentrated in a single functional land, such as residential land [4-6], industrial land [7-8], commercial services land [9-10] and so on, especially the study of residential land is more outstanding. But, the evolution of various of functional land is relatively few.

Oasis city is a unique urban type in arid area. Studying the evolution of oasis city's functional land cannot only clarify its space response to agglomeration and diffusion of urban functional land, and can mine characteristics and inner regularity of oasis city's spatial expansion. It is more significant for the oasis city under the dual restriction of fragile ecological environment and scarce soil-water resources. Based on these, this paper takes the downtown of Zhangye, a typical oasis city in the Hexi Corridor in Northwest of China, as an example and uses the GIS tools and methods to analyze the evolution characteristics of residential land, industrial land and public service land since 1981, so as to provide a case guidance for the sustainable development of oasis city in the new period. 


\section{Study Area \& Methodology}

\subsection{Study Area}

Zhangye located in the central hinterland of the Hexi Corridor, which has wide and flat topography, less precipitation and widespread river, is a typical oasis city in arid area. Benefiting by the predominant natural conditions and geographical advantages, Zhangye is an important city in ancient Silk Road, national historical and cultural city, one of the country's major commodity grain base and a node city in Silk Road Economic Belt, known as gold Zhangye. The downtown of Zhangye City chosen by referring to the urban master planning of Zhangye from 2012 to 2020. Its scope owns an area of $76.86 \mathrm{~km}^{2}$ and a population of about 28.57 million, surrounded by East Third Ring Road, West Third Ring Road, South Third Ring Road, Riverside Avenue and Changyun Road, etc.

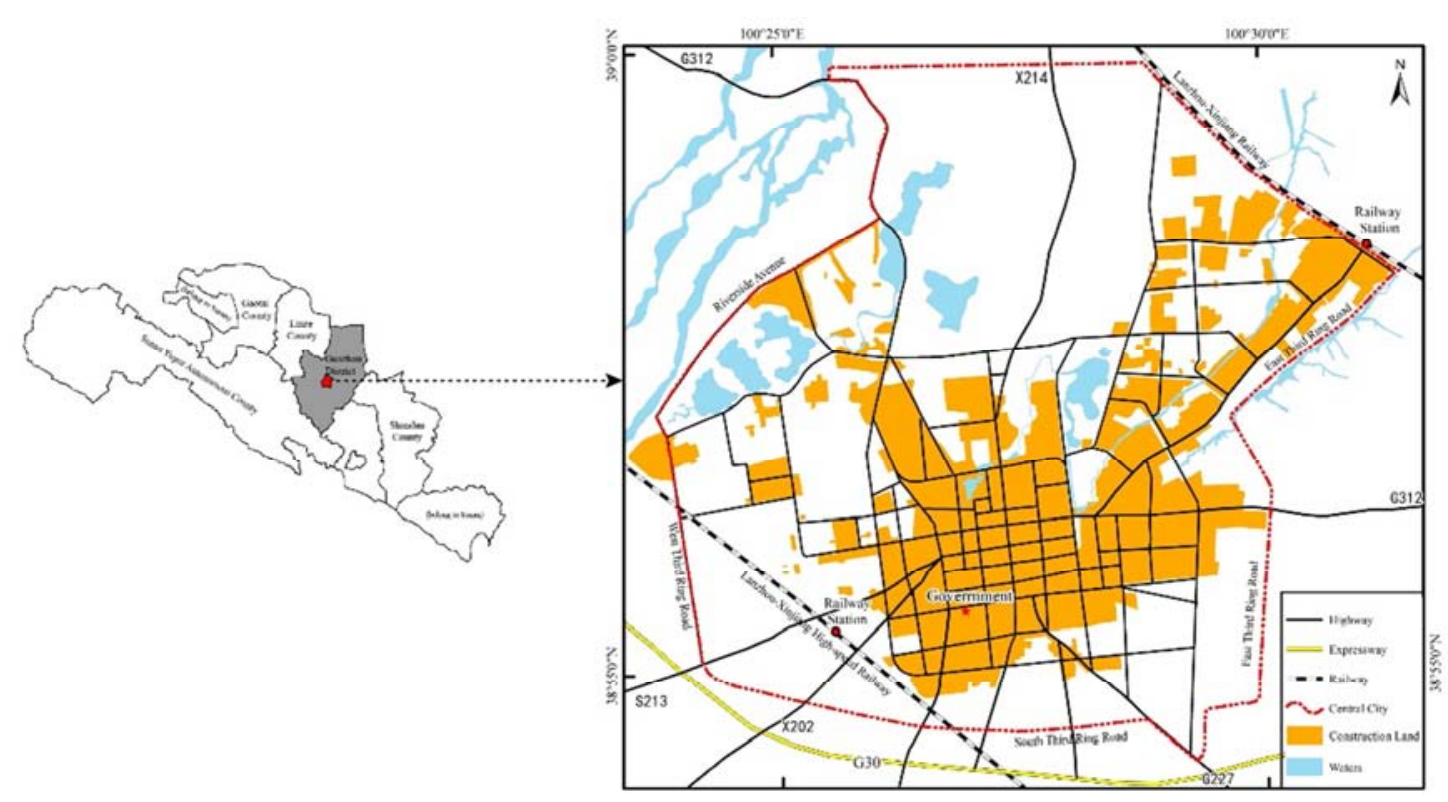

Figure 1. Map of center urban area of Zhangye City.

\subsection{Methodology}

\subsubsection{Obtaining of Urban Functional Land}

The urban functional land data are obtained from the urban land-use status maps $(1981,2004,2014)$ and the topographic map $(1: 50,000)$ of Zhangye central town. Based on the topographic map, we correct the urban land-use status maps respectively and obtain residential land, industrial land (including storage land), public services land (including administrative land, business land, medical land, education land, etc.) and construction land from the corrected urban land-use maps by referring the urban land classification standard and using ArcGIS software.

\subsubsection{Methods}

(1) Expansion Dynamic Index of Single Functional Land

The expansion dynamic index of single functional land refers to the average annual expansion area of a kind of functional land, which aims to reveal the strength and speed of the expansion of a certain functional land within a certain period [11-12]. Its expression as follows:

$$
R=\frac{\left(U_{b}-U_{a}\right) \times 100}{U_{a} \times T}
$$

In this expression, $R$ is the expansion dynamic index of a functional land, $U_{b}$ is the area of a functional land at end of the study, $U_{a}$ is the area of a functional land at beginning of the study, $T$ is time (years).

(2) Kernel Density Estimation

Kernel Density Estimation can analyze the spatial distribution density of every kind of urban functional land and can reveal the agglomeration and diffusion of every urban functional land $[2,13]$. In this paper, we take the area as the weight index and adapt the Natural Break to divide every urban functional land into three classes: high-density area, middle-density area and low-density area. Finally, we get the figure of spatial distribution density of every functional land.

\section{Spatial-Temporal Evolution Characteristics of Urban Functional Land}

\subsection{Structural Evolution of Main Urban Functional Land}

The construction land area of downtown increased from $5.88 \mathrm{~km}^{2}$ in 1981 to $23.27 \mathrm{~km}^{2}$ in 2014 with an average annual increase of $0.49 \mathrm{~km}^{2}$ and an average annual increase rate of $8.45 \%$. Seen from the Table 1 and Figure 2, the area of residential land increased from $0.88 \mathrm{~km}^{2}$ in 1981 to 6.48 $\mathrm{km}^{2}$ in 2014 , and its proportion in urban construction land 
increased gradually. The area of the industrial land increased from $1.46 \mathrm{~km}^{2}$ in 1981 to $5.06 \mathrm{~km}^{2}$, but its proportion in urban construction land gradually decreased. The area of public service land increased from $1.17 \mathrm{~km}^{2}$ in 1981 to $6.91 \mathrm{~km}^{2}$, and the proportion in urban construction land increased gradually. These show that the proportion of residential land and public service land occupy the majority of urban construction land and increases significantly. They are the main driver of urban spatial expansion.

Different urban function land shows different trends in different time periods seen from Table 2 and Figure 3. From 1981 to 2004 , the residential land's expansion dynamic index was the highest and the area of its increased by $3.04 \mathrm{~km}^{2}$, indicating that with more population influx into the city, the housing demand increase correspondingly. From 2004 to 2014, expansion dynamic index of the public service land was the highest, and its area increased by $5.74 \mathrm{~km}^{2}$. It indicated the demand for high quality city public service was greater than the demand for housing.

Table 1. Area and proportional change of main functional land in Zhangye City.

\begin{tabular}{|c|c|c|c|c|c|c|}
\hline \multirow{2}{*}{ Types } & \multicolumn{2}{|l|}{1981} & \multicolumn{2}{|l|}{2004} & \multicolumn{2}{|l|}{2014} \\
\hline & $\operatorname{Area}\left(\mathbf{k m}^{2}\right)$ & Proportion (\%) & $\operatorname{Area}\left(\mathrm{km}^{2}\right)$ & Proportion(\%) & $\operatorname{Area}\left(\mathrm{km}^{2}\right)$ & Proportion (\%) \\
\hline Residential land & 0.88 & 14.97 & 3.92 & 22.78 & 6.48 & 27.85 \\
\hline Industrial land & 1.46 & 24.83 & 3.85 & 22.37 & 5.06 & 21.74 \\
\hline Public service land & 1.17 & 19.89 & 3.57 & 20.74 & 6.91 & 29.69 \\
\hline Construction land & 5.88 & 100 & 17.21 & 100 & 23.27 & 100 \\
\hline
\end{tabular}

Table 2. Dynamic degrees of main functional land in Zhangye City.

\begin{tabular}{|c|c|c|c|c|}
\hline Period & Residential land & Industrial land & Public service land & Construction land \\
\hline 1981-2004 & 15.02 & 7.12 & 8.92 & 7.90 \\
\hline 2004-2014 & 6.53 & 3.14 & 9.36 & 4.05 \\
\hline
\end{tabular}

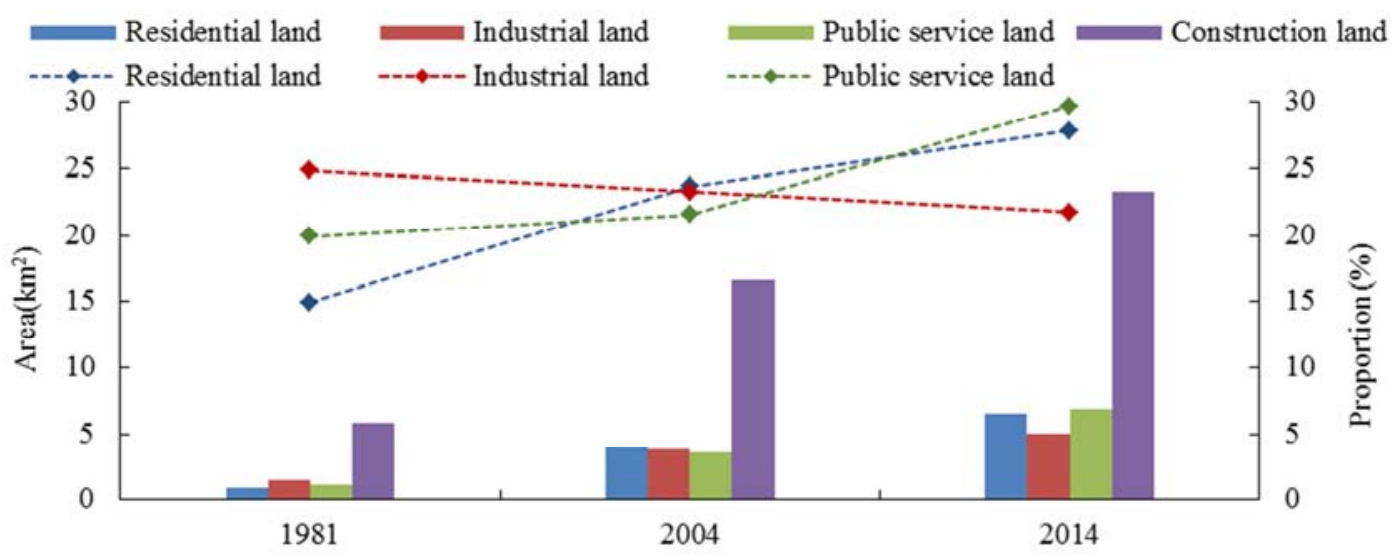

Figure 2. Structure of main functional land in Zhangye City.

\subsection{Agglomeration and Diffusion of Main Functional Land}

(1) Residential land

Seeing from the Figure 3(a), it found that with the urban scale expanding out, the residential land overall presents the trend of spreading outward from the central city and experiences the process of gather from the old inner to spread to each position. In 1981, the high-density area and middle-density area of residential land were mainly located in the both side of East Avenue and West Avenue and surround the Ganquan Park, the Great Buddhist Temple and the railway station. In 2004, the residential land expanded across the first ring road. The range of high-density area and middle-density area is obviously expanded, which is basically connected to a slice. They concentrated in the old city, especially in the north and east of the downtown city. Compared with the previous period, factories relocating out provide more space for replacement of the residential land, especially the construction of new residential area and the replacement of industrial land, making the living space is greatly improved. In 2014, the residential land has clearly crossed the second ring road and expanded westward and southward. The high-density area scattered on both sides of the Ganguan Park, along the Juyan Road, nearby the Riverside New Area and the entrance of Zhangye-Su'nan Road, and combine with the public service land. The middle-density area scattered along the main traffic artery. The housing environment had been greatly improved compared with period, and more middle or high grade residential quarters were built in the western Riverside New Area. This illustrates that the residential land pushes the urban space toward the outer edge.

(2) Industrial land

Based on the Figure 3(b), it found that with urban space expanding out and adjustment of urban functional land, the industrial land shows a trend that from scattered distribution to concentrated in the industrial park. In 1981, the high-density area and middle-density area were scatteredly distributed in the old city and the south of the railway station, and they 
mixed with the residential land. In 2004, the high-density area and middle-density area were concentrated in the front of the railway station, the industrial park and along the Zhang-Huo Road. At the same time, some storage and low-pollution, low-energy industrial land were scattered in the old city area. During this period, due to the Zhangye Industrial Park developed gradually to large scale, high energy consumption, high pollution of industrial enterprises gradually moved to the industrial park, some light textile industry, brewery and flour mills factory and part of storage land only distribute in the old city area. In 2014, the industrial park was more concentrated with a small amount of storage land scattered in the old city area. In general, the industrial land has gradually expanded the urban space to the northeast of downtown, forming a new growth pole.

(3) Public service industrial

According to Figure 3(c), a trend can be found that the public service land spread outward from the central city. In 1981, the high-density area and middle-density area were concentrated in the southwest of downtown and both sides of the South Avenue. During this period, the public service land was mainly concentrated in the old city area, and they mixed with the residential land. In addition, they were mainly commercial and administrative land. In 2004, the high-density area spread out from the old city area and concentrated in to the northwest of downtown with medical and education land. And, the middle-density area mainly concentrated on the both sides of the East Avenue, the West Avenue and the South Avenue and were commercial land. Compared to the previous period, new high-density area were mainly the administrative land in the southwest of the downtown, the tourism and leisure land in the national wetland park, and commercial land near the railway station square in 2014. And, the middle-density areas were scattered on both sides of the main road and the Riverside New Area. On the whole, the public service land has gradually spread to the periphery accompanied by the residential land, which together constitutes the booster of urban space extending.
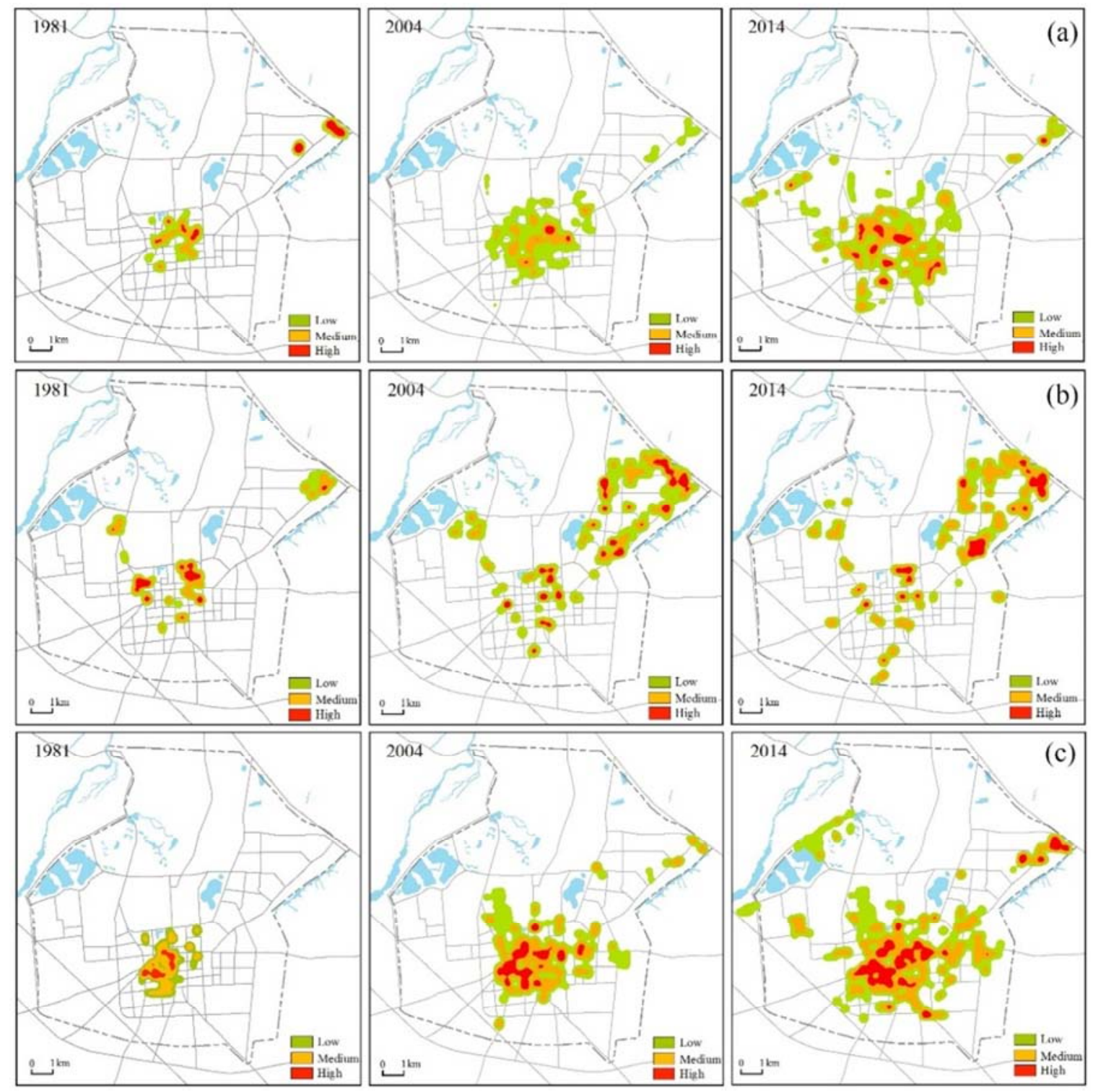

Figure 3. Spatial distribution density of the residential land (a), the industrial land (b) and the public service land (c). 


\section{The Situation of Urban Space Structure and the Future Regulation Strategy}

It can see from Figure 4 that Zhangye's urban spatial structure still is one core. Although the urban space structure has been formed two development axes and three rings, urban functional partition still exists the problem that functional area is mixed. Under the restriction of soil and water resources, whether undertake more advanced urban functions is the key of Zhangye becomes a node city of the Silk Road Economic Belt. However, urban space optimization will provide the foundation for the urban function transformation and ascension, but improving the intensive level of urban land-use and selecting the mode of urban space structure is the key to urban space optimization.

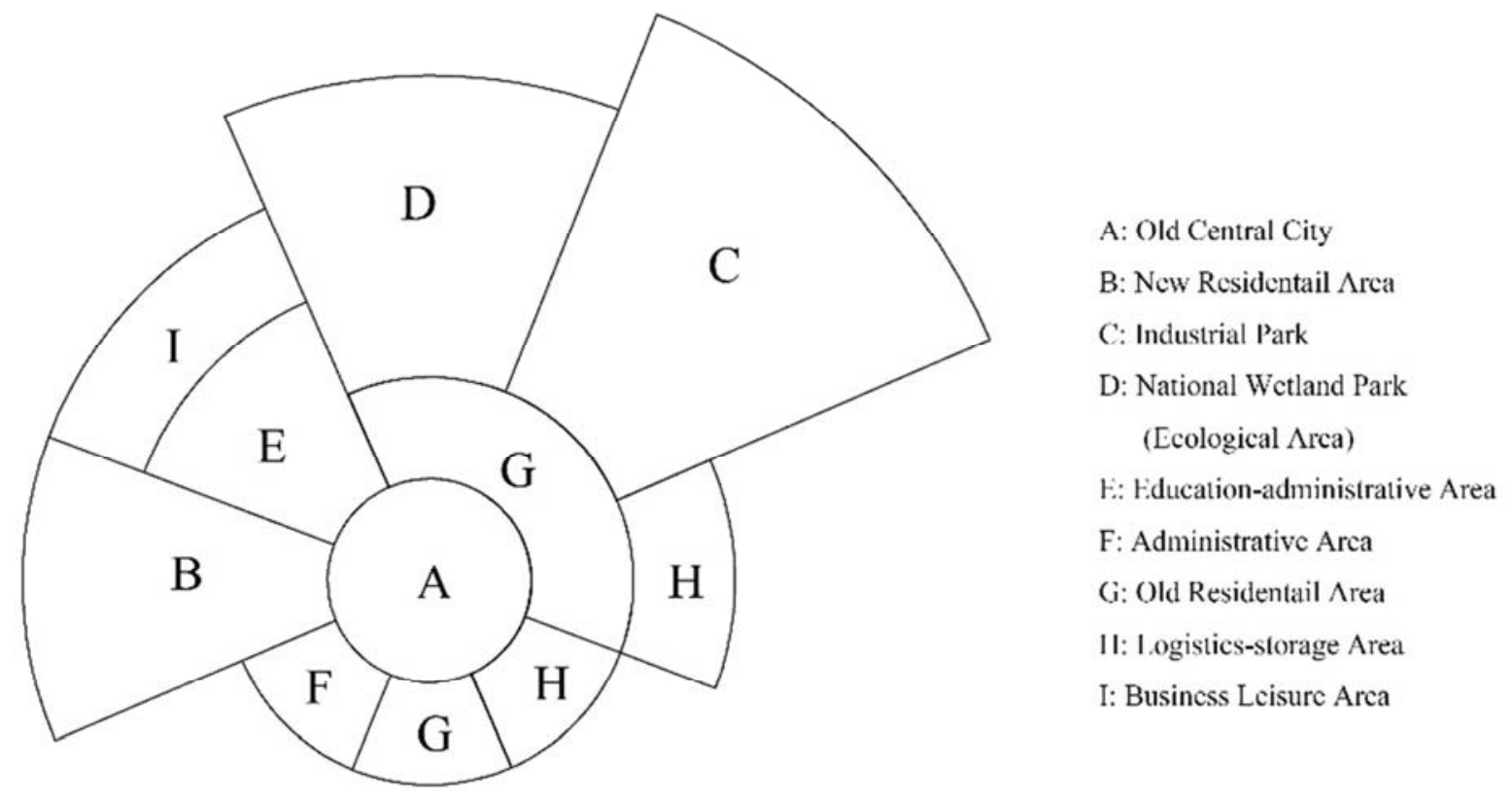

Figure 4. The situation of urban spatial structure in Zhangye City.

\subsection{Improve the Intensive and Economical Use of Urban Land and Promote the Development of Compact Urban}

Due to the lack of evaluation of suitability, evaluation of bearing capacity and urban planning in the past, main urban functional lands were scattered, leading to the efficiency of urban land-use was low and then causing a large number of excellent farmland wasted. Therefore, it is urgent to improve the comprehensive utilization ratio of urban land, actively carry out the evaluation of the intensive and economical use of urban land, and fully tap the potential of urban land, so as to promote the development of urban compact space. To solve the above problem, some suggestions should be adopted. Firstly, Zhangye should make use of the land reserve system to integrate the idle land in the built-up area and fully develop and utilize the urban land. Secondly, Zhangye should reform the low-level, low-density and old buildings, improve the carrying capacity of buildings, and improve the public infrastructure, so as to make urban land transform from extensive and quantitative to efficient and intensive. Thirdly, Zhangye should repair the damaged land, the abandoned industrial and mining land and arable land, increase urban land storage and improve the quality of land resources. Lastly, Zhangye should empower reasonably the urban underground space and enlarge the ecological land, encouraging urban space transforming to sponge city.

\subsection{Breakthrough the Development Mode of Single Core and Construct the Complete Urban Space Structure}

According to the demand of urban overall development and the policies of urban function division, Zhangye should break through the closed pattern of concentric radial. In the future, Zhangye should promote comprehensive service function of the old city to form the urban core area, intensify the construction of the Riverside New Area to form a secondary service center, upgrade the scientific and technological content of the industrial parks to form the urban business center, strengthen the protection of wetland ecological areas to form the urban eco-tourism and leisure center and include the Tuerbatan Industrial Park into the urban construction area to form the circular economy park, forming finally the urban space structure with one core, one park and three centres.

\section{Result and Discussion}

As a result of the limit of the city scale and time of city planning, this paper only analyzes the evolution characteristics of three functional lands and focusses on the urban land-use. The conclusion may not reveal the deeply objective regularity of evolution of urban functional lands. In addition, the game of ecological protection with urban 
development and the limit of water and soil resources restricts the oasis city' s space development. Discussing the coupling of oasis city's functional space and ecological environment will be an important direction for the next research.

\section{Conclusion}

Since 1981, the proportion of the residential land and the public service land has been increasing in urban construction land year by year, and they have been spread from the old urban district to the outskirts. They are the booster of urban spatial expansion. Although the proportion of the industrial land has declined in urban construction land, it has been distributed from the old city to the park, which is the driving force to guide urban spatial expansion. Due to the lack of reasonable planning of urban space in the past, urban functional lands have retreated and adjusted with large-scale, but there are still low quality of living and a large number of industries land in downtown. It reduces the public service function of central urban area and then affect the healthy development. In order to solve these problems, Zhangye should improve the conservation and intensive use of urban land, break through the development mode with single center, promote the construction of compact urban space and form complete urban space structure.

\section{Acknowledgements}

We greatly appreciate the editor for the improvement of this paper. We also appreciate the manuscript improvement suggestions from reviewers. This study was supported by a project of the National Natural Science Foundation of China (No. 41271133).

\section{References}

[1] Li Q L, Ma X D, Shen Z P. Analysis of evolution of urban internal spatial structure in Yancheng based on GIS. Chinese Human Geography, 2009, 110(6): 50-54.

[2] Zhou G L, Li C G, Zhang J, et al. Transition of urban functional land in Changchun from 2003 to 2012. Acta Geographica Sinica, 2015, 70(4): 539-550
[3] Sun P J, Xiu C L. Progress in Research on Urban Spatial Expansion of China. Areal Research and Development, 2014, 33(4): 46-52.

[4] Song W X, Wu Q Y, Zhu X G. Residential differentiation of Nanjing in the new period. Acta Geographica Sinica, 2010, 65(6): 685-694.

[5] Liao B G, Xu J G, Mei A X. Evolution of residential differentiation in central Shanghai City (1947-2007): A view of residential land use types. Geographical Research, 2012, 31(6): 1089-1102.

[6] Zhou C S, Luo R Z, Dai D D. Evolution and mechanism of the residential spatial structure from 2000 to 2010 in Guangzhou. Geographical Research, 2015, 34(6): 1109-1124.

[7] Zhang J, Li C G, Zhou G L, et al. The evolution pattern and mechanism of public service facilities lands in Changchun [J]. Acta Geographica Sinica, 2015, 70(12): 1939-1952.

[8] Chen Y, Chen Y R, Ma W B. Evaluation of industrial land's intensive use and analysis of potential mining with Bayes discrimination: a case study of typical enterprises in Hubei Province. Resources Science, 2012, 34(3): 433-441.

[9] Wen F H, Xu X Q. The development of business office space of Guangzhou and its coupling relationship with the urban space. Chinese Human Geography, 2011, 26(2): 36-43.

[10] Zhang J, Li C G, Zhou G L, et al. The evolution pattern and mechanism of public service facilities lands in Changchun. Acta Geographica Sinica, 2015, 70(12): 1939-1952.

[11] Tao J, Lu Y Q, Wang C Y. A study on urban land conversion and mechanism in Urumqi City. Chinese Economic Geography, 2008, 28(6): 1025-1030.

[12] Shen Q X, Li C G, Zhou G L, et al. The coupling of functional urban spaces: a case study of Changchun from 2002 to 2012. Geographical Research, 2015, 34(10): 1897-1910.

[13] Shang Z Y, Zhang X L, Lu X X, et al. Evolution of accessibility spatial pattern of urban land use: a case of Huai'an City in Jiangsu Province. Scientia Geographica Sinica, 2014, 34(2): 154-162.

[14] Tian G J, Wu J G, Yang Z F. Spatial pattern of urban functions in the Beijing metropolitan region. Habitat International, 2010, 34(2): 249-255. 